\title{
Renal replacement therapy associated with lithium nephrotoxicity in Australia
}

\section{Milton Roxanas \\ MB BS, FRANZCP, Associate Professor of Psychiatry \\ Blair S Grace $\mathrm{PhD}, \mathrm{BSc}$, \\ Research Fellow \\ Charles R P George MB BS, PhD, FRACP Clinical Associate Professor of Nephrology \\ 1 Concord Hospital Sydney, NSW. \\ 2 Australia and New Zealand Dialysis and \\ Transplant Registry. Adelaide, SA. \\ blair@anzdata.org.au}

MJA 2014; 200: 226-228 doi: 10.5694/mjal3.10435 n 1949, John Cade reported the use of lithium in the treatment of manic-depressive illness, thus ushering in the era of psychopharmacology. ${ }^{1}$ Clinicians soon observed that patients receiving long-term lithium therapy developed polyuria, suggesting that it might cause renal tubular damage. ${ }^{2}$ Many years later, evidence arose that it might also reduce renal function, although the initial report included some patients with lithium toxicity. $^{3}$ A meta-analysis of 1172 patients across 14 studies found that $15 \%$ of patients had a reduced glomerular filtration rate (GFR). ${ }^{4}$ This led to a discussion of the lithium level sufficient to control symptoms but not to create permanent renal damage. ${ }^{5}$

Controversy regarding the level of risk persisted. One authority rejected the possibility of renal damage; ${ }^{6}$ however, a recent meta-analysis of 365 studies disagreed with this but concluded that the risk of renal replacement therapy (RRT) was low (18/3369 patients $[0.5 \%]){ }^{7}$

The need for an epidemiological survey was advocated; ${ }^{8}$ however, until now, this has only been done within restricted geographical foci, with uncertain denominators associated with incidence rates. A study involving two Paris hospitals and a questionnaire sent to all nephrologists in France found that $0.22 \%$ of all RRT patients had received lithium treatment, without any other symptoms of lithium intoxication. ${ }^{9}$ A Swedish study of two regions found that $0.81 \%$ of RRT patients had kidney disease attributed to lithium-induced nephropathy ( $\mathrm{LiN})$, and $1.2 \%$ of lithiumtreated patients had raised serum creatinine levels. These patients had consumed lithium for at least 12 years and their incidence of end-stage renal disease (ESRD) was sixfold greater than that of the general population. ${ }^{10}$ Another study found that patients receiving lithium for 15.6 years had a lower GFR compared with that of controls. ${ }^{11}$ The evidence suggests that ESRD occurs after long exposure to lithium, up to 23 years. ${ }^{10-12}$

\section{Abstract}

Objective: To analyse the annual incidence of end-stage renal disease (ESRD) associated with lithium-induced nephropathy ( $\mathrm{LiN}$ ) in Australia.

Design, setting and participants: Retrospective cohort study of patients commencing renal replacement therapy (RRT) in Australia. We compared patients with LiN with all other RRT patients between 1 January 1991 and 31 December 2011, using Australia and New Zealand Dialysis and Transplant Registry data.

Main outcome measures: Numbers and characteristics of incident RRT patients, primary kidney disease (LiN or other, based on clinical diagnosis).

Results: LiN contributed to 187 people in Australia commencing RRT between 1 January 1991 and 31 December 2011. The incidence rate increased from 0.14 cases/million population/year $(95 \% \mathrm{Cl}, 0.06-0.22)$ in 1992-1996 to 0.78 (95\% $\mathrm{Cl}, 0.67-0.90)$ in 2007-2011. This increase is unlikely to be attributed solely to demographic changes in Australia. LiN patients were more likely than non-LiN patients to be women, to be white, to smoke, and to have a higher body mass index, but were less likely to have undergone renal biopsy.

Conclusions: Rates of ESRD attributed to LiN are increasing rapidly. Currently accepted lithium dosages and duration of treatment might induce ESRD in a large cohort of patients. We encourage clinicians to exercise discretion when prescribing lithium, check renal function regularly, stop lithium if there is a deterioration in two consecutive readings, and consider substitution with other drugs.

Our study addresses the need for a nationwide survey of the epidemiology of ESRD associated with LiN. We investigated details of all patients commencing RRT within Australia with clinically diagnosed LiN. Analysis was performed on a de-identified data extract from the Australia and New Zealand Dialysis and Transplant Registry (ANZDATA). Release of the data for this purpose was approved by the ANZDATA Executive.

\section{Methods}

We collected data from ANZDATA for all patients who commenced RRT with renal failure attributed to lithium toxicity between 1 January 1991 and 31 December 2011. We compared these patients with those who commenced RRT with renal failure due to other causes over the same period. We noted whether patients at the time of commencing RRT were smokers, whether diagnosis was via biopsy (available after 1 April 1997), and serum creatinine levels at time of entry (available after 1 April 1998). Estimated GFR was calculated using the four-variable Modification of Diet in Renal Disease formula. ${ }^{13}$ ANZ-
DATA contains information about patients who receive chronic RRT (dialysis or transplantation) in Australia, ${ }^{14}$ and is noted for its completeness. We used Australian Bureau of Statistics information concerning number, age and sex distribution of the Australian population. ${ }^{15}$

We used Pearson $\chi^{2}$ and MannWhitney $U$ tests to compare patient characteristics between groups. We compared biopsy rates and trends over time between $\mathrm{LiN}$ and other patients using logistic regression, with time by LiN interaction included. We directly standardised incidence rates for age and sex to the 1 June 2006 Australian population, with age in 10year cohorts for patients aged 0-79 years, then a single cohort of patients aged $\geqslant 80$ years. We used linear regression to investigate changes in age of commencing RRT, and Poisson regression to investigate the mean number of comorbidities.

\section{Results}

No patients commenced RRT associated with LiN before 1991. However, between 1991 and 2011, 187 patients did so, compared with 38316 
1 Characteristics of patients commencing renal replacement therapy (RRT) with lithium-induced nephropathy and all other patients in Australia, 1991-2011

\begin{tabular}{|c|c|c|c|}
\hline Characteristic & $\begin{array}{l}\text { No. }(\%)^{*} \text { of patients with } \\
\text { lithium-induced nephropathy }\end{array}$ & $\begin{array}{l}\text { No. }(\%)^{*} \text { patients with other } \\
\text { types of kidney disease }\end{array}$ & $P$ \\
\hline Number of patients & 187 & 38316 & \\
\hline Median age, years (IQR) & $60(53-66)$ & 61 (47-71) & 0.99 \\
\hline Men & $76(40.6 \%)$ & $22714(59.3 \%)$ & $<0.001$ \\
\hline Diabetes & $28(15.0 \%)$ & $14133(36.9 \%)$ & $<0.001$ \\
\hline Median body mass index, $\mathrm{kg} / \mathrm{m}^{2}$ (IQR) & $28(23-33)$ & $26(22-30)$ & $<0.001$ \\
\hline Smoker & $38(20.3 \%)$ & $4749(12.4 \%)$ & 0.001 \\
\hline Median eGFR, mL/min/1.73 m² (IQR) & $7.2(5.4-9.9)$ & $7.2(5.3-9.7)$ & 0.78 \\
\hline European ancestry & $183(97.9 \%)$ & $30733(80.2 \%)$ & $<0.001$ \\
\hline Biopsy $^{\dagger}$ & $42(22.4 \%)$ & 10079 (26.3\%) & \\
\hline
\end{tabular}

2 Number of patients commencing renal replacement therapy (RRT), 1987-2011

\begin{tabular}{|c|c|c|c|c|}
\hline Years & $\begin{array}{c}\text { No. of patients receiving } \\
\text { lithium }\end{array}$ & $\begin{array}{l}\text { Crude incidence rate/year/ } \\
\text { million population }(95 \% \mathrm{Cl})\end{array}$ & $\begin{array}{l}\text { Standardised incidence } \\
\text { rate/year/million population } \\
(95 \% \mathrm{Cl}) *\end{array}$ & $\begin{array}{c}\text { Proportion of all incident RRT } \\
\text { patients }(95 \% \mathrm{Cl})\end{array}$ \\
\hline 1987-1991 & $2^{\dagger}$ & $0.02(0-0.07)$ & $0.02(0.00-0.07)$ & $0.20 \%(0-0.49 \%)$ \\
\hline 1992-1996 & 12 & $0.14(0.06-0.22)$ & $0.13(0.05-0.21)$ & $0.19 \%(0.08 \%-0.30 \%)$ \\
\hline 1997-2001 & 36 & $0.36(0.20-0.52)$ & $0.32(0.18-0.47)$ & $0.40 \%(0.27 \%-0.53 \%)$ \\
\hline $2002-2006$ & 52 & $0.51(0.42-0.59)$ & $0.43(0.36-0.51)$ & $0.48 \%(0.35 \%-0.62 \%)$ \\
\hline 2007-2011 & 85 & $0.78(0.67-0.90)$ & $0.65(0.54-0.76)$ & $0.70 \%(0.55 \%-0.85 \%)$ \\
\hline
\end{tabular}

patients who commenced RRT with renal disease attributed to other causes.

LiN patients were more likely than other patients to be women, to be white, to smoke and to have a higher body mass index, but were of similar age and less likely to have undergone renal biopsy (Box 1). Among $172 \mathrm{LiN}$ patients with available data, 42 (22.4\%) underwent a diagnostic kidney biopsy. Biopsy rates of LiN patients decreased over time (odds ratio per year, 0.74; 95\% CI, 0.64-0.84; $P<0.001)$, which was more rapid than biopsy rates in non-LiN patients $(P<0.001$ for the time by LiN interaction).

The number of patients commencing RRT associated with LiN increased over time, both in raw numbers, per population and as a proportion of all RRT patients. There were 0.14 cases per million population per year (95\% CI, 0.06-0.22) in 1992-1996 and 0.78 (0.67-0.90) in 2007-2011. As a proportion of all incident RRT patients, LiN increased from $0.19 \%$ in 1992-1996 to $0.70 \%$ in 2007-2011 (Box 2). Age- and sex-standardised incidence rates were slightly lower than crude incidence rates for recent years (Box 2 and Box 3 ).

\section{Discussion}

We found a marked increase in the incidence of clinically diagnosed LiN leading to RRT, rising from 0.14 cases per million population per year in 1992-1996 to 0.78 in 2007-2011. LiN accounted for $0.19 \%$ of all new RRT cases in 1992-1996, and $0.70 \%$ in 2007-2011. The former figure is close to the incidence reported in France in the late 1990s, ${ }^{9}$ while the latter is close to the incidence found in a recent Swedish study $(0.81 \%) .{ }^{10}$ The similarity between standardised and crude incidence rates suggests that demographic changes do not explain the increase in the incidence of LiN.

Registry data have some limitations. Some cases of LiN may have been missed, especially early in the time series, when awareness of $\mathrm{LiN}$ may have been low. LiN is largely a clinical diagnosis, and most patients do not undergo biopsy. LiN patients commencing RRT were less likely to undergo biopsy, and rates are decreasing compared with those for other RRT patients. Diagnostic bias is possible with any registry data. Nephrologist awareness of irrever- sible LiN may have increased over time, with the publication of recent epidemiological studies ${ }^{10}$ and a systematic review. ${ }^{7}$ As such, the propensity to diagnose $\mathrm{LiN}$ as a cause of ESRD may have increased over time. Unknown confounders may also potentially increase rates of both bipolar disorder and kidney disease. Existing data do not allow us to determine numbers of patients with ESRD associated with $\mathrm{LiN}$ who are not

3 Crude incidence rates of renal replacement therapy associated with clinically diagnosed lithium-induced nephropathy in Australia, 1991-2011

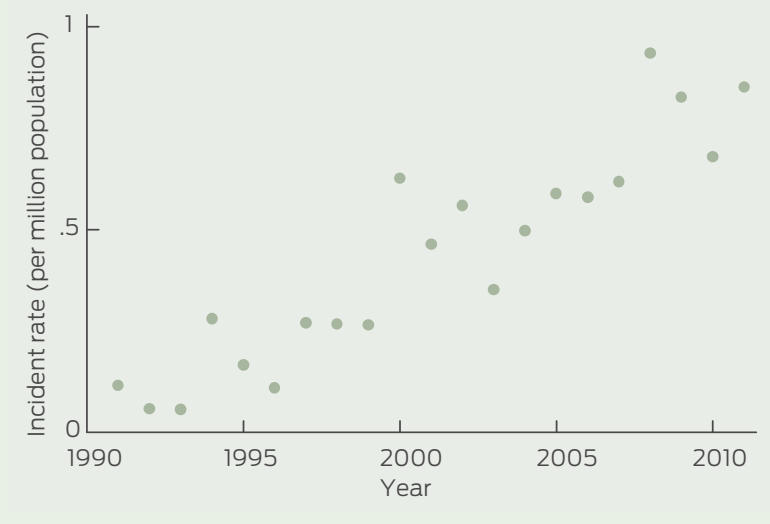


recorded in ANZDATA, because they do not receive RRT. However, most people with ESRD in Australia do commence RRT. ${ }^{16}$ Data on the number of patients receiving long-term lithium treatment in Australia are not readily available.

We conclude that $\mathrm{LiN}$ is an uncommon cause of ESRD but is becoming more common. Many cases of LiN could be avoided through careful diagnosis of bipolar illness, restricted prescription of lithium, and careful follow-up of lithium serum levels and renal function. Improved record keeping, such as a lithium-monitoring book $^{17}$ or electronic records, is important. We suggest that renal function (based on estimated GFR derived from serum creatinine levels, and proteinuria tests) and serum lithium levels should be monitored more frequently than 6 months, and certainly more than every 12 months, which some authors have suggested. ${ }^{18}$ This is most important for patients who have received lithium for many years. Clinicians should consider stopping lithium and using other suitable mood stabilisers (eg, sodium valproate ${ }^{19}$ ) if two consecutive readings suggest decreasing renal function, or if the estimated GFR is $<45 \mathrm{~mL} / \mathrm{min} / 1.73 \mathrm{~m}^{2}{ }^{20}$

Acknowledgements: We thank the staff of renal units throughout New Zealand for their efforts in submitting information to ANZDATA, and the staff of ANZDATA for maintaining the database. Philip Clayton (ANZDATA and University of Sydney) and Matthew Cervelli (Central Northern Adelaide Renal and Transplantation Services) provided valuable input into earlier drafts.

Competing interests: No relevant disclosures.

Received 3 Apr 2013, accepted 10 Oct 2013.

1 Cade JF. Lithium salts in the treatment of psychotic excitement. Med J Aust 1949: 349-352.

2 Trautner EM, Morris R, Noack CH, Gershon S. The excretion and retention of ingested lithium and its effects on the ionic balance of man. Med J Aust 1955; 42: 280-291.

3 Hestbech J, Hansen HE, Amdisen A, Olsen S. Chronic renal lesions following long-term treatment with lithium. Kidney Int 1977; 12 205-213.

4 Boton R, Gaviria M, Batlle DC. Prevalence, pathogenesis, and treatment of renal dysfunction associated with chronic lithium therapy. Am J Kidney Dis 1987; 10: 329-345.

5 George CR. Renal aspects of lithium toxicity. Med Aust 1989; 150: 291-292.

6 Schou M. Lithium. In: Dukes MNG, Beeley L, editors. Side effects of drugs annual. Amsterdam: Elsevier, 1990.

7 McKnight RF, Adida M, Budge K, et al. Lithium toxicity profile: a systematic review and metaanalysis. Lancet 2012; 379: 721-728.

8 Wells JE, Cross NB, Richardson AK. Toxicity profile of lithium. Lancet 2012; 379: 2338.

9 Presne C, Fakhouri F, Noël LH, et al. Lithiuminduced nephropathy: rate of progression and prognostic factors. Kidney Int 2003; 64: 585-592.
10 Bendz H, Schön S, Attman PO, Aurell M. Renal failure occurs in chronic lithium treatment but is uncommon. Kidney Int 2010; 77: 219-224.

11 Tredget J, Kirov A, Kirov G. Effects of chronic lithium treatment on renal function. J Affect Disord 2010; 126: 436-440.

12 Janowsky D, Buniviciute J, Hu Q, Davis JM. Lithium-induced renal insufficiency: a longitudinal study of creatinine increases in intellectually disabled adults. J Clin Psychopharmacol 2011; 31: 769-773.

13 Levey AS, Greene T, Kusek JW, Beck GL; MDRD Study Group. A simplified equation to predict glomerular filtration rate from serum creatinine. J Am Soc Nephrol 2000; 11: A0828.

14 Australia and New Zealand Dialysis and Transplant Registry. Thirty fifth annual report. McDonald S, Clayton P, Hurst K, editors. Adelaide: ANZDATA, 2012

15 Australian Bureau of Statistics. Australian demographic statistics, Mar 2012. Canberra: ABS, 2012. (ABS Cat. No. 3101.0.)

16 Sparke C, Moon L, Green F, et al. Estimating the total incidence of kidney failure in Australia including individuals who are not treated by dialysis or transplantation. Am J Kidney Dis 2013; 61: 413-419.

17 Gerrett D, Lamont T, Paton C, et al. Prescribing and monitoring lithium therapy: summary of a safety report from the National Patient Safety Agency. BMJ 2010; 341: c6258.

18 Malhi GS, Tanious M, Bargh D, et al. Safe and effective use of lithium. Austral Prescriber 2013; 31: 18-21.

19 Bowden C, Gogus A, Grunze H, et al. A 12-week, open, randomized trial comparing sodium valproate to lithium in patients with bipolar disorder suffering from a manic episode. Int Clin Psychopharmacol 2008; 23: 254-262.

20 Kripalani M, Shawcross J, Reilly J, Main J. Lithium and chronic kidney disease. BMJ 2009; 339: b2452. 